\title{
BMJ Open Association of rheumatoid arthritis and high sodium intake with major adverse cardiovascular events: a cross-sectional study from the seventh Korean National Health and Nutrition Examination Survey
}

\author{
Jeong-Hyeon Bae, ${ }^{1}$ Min-Young Shin, ${ }^{1}$ Eun Ha Kang, ${ }^{2}$ Yun Jong Lee (D) , \\ You-Jung $\mathrm{Ha}$ (1) ${ }^{2}$
}

To cite: Bae J-H, Shin M-Y, Kang EH, et al. Association of rheumatoid arthritis and high sodium intake with major adverse cardiovascular events: a cross-sectional study from the seventh Korean National Health and Nutrition Examination Survey. BMJ Open 2021;11:e056255. doi:10.1136/ bmjopen-2021-056255

- Prepublication history and additional supplemental material for this paper are available online. To view these files, please visit the journal online (http://dx.doi.org/10.1136/ bmjopen-2021-056255).

Received 08 August 2021 Accepted 12 November 2021

A) Check for updates

(c) Author(s) (or their employer(s)) 2021. Re-use permitted under CC BY-NC. No commercial re-use. See rights and permissions. Published by BMJ.

${ }^{1}$ Seoul National University College of Medicine, Seoul, Republic of Korea

${ }^{2}$ Division of Rheumatology, Department of Internal Medicine, Seoul National University Bundang Hospital, Seongnam, Republic of Korea

Correspondence to

Dr You-Jung Ha;

hayouya@snubh.org

\section{ABSTRACT}

Objectives High salt intake has a harmful effect on hypertension; however, the association between major adverse cardiovascular events (MACE) and salt intake is still controversial. Rheumatoid arthritis (RA) is also characterised by excess cardiovascular risk. However, few studies have investigated the combined role of salt intake and RA in MACE in the general Korean population. Here, we evaluated this relationship among the Korean adult population.

Design Retrospective, cross-sectional.

Setting Population-based survey in Korea.

Methods This study was based on the data of the seventh Korean National Health and Nutrition Examination Survey (2016-2018). The estimated 24-hour urinary sodium excretion (24HUNa), a surrogate marker for daily sodium intake, was calculated using the Tanaka equation and was stratified into five groups $(<3,3-3.999,4-4.999$, 5-5.999 and $\geq 6 \mathrm{~g} /$ day). Finally, data from 13464 adult participants (weighted $n=90425888$ ) were analysed; all analyses considered a complex sampling design. Multivariable logistic regression for MACE as primary dependent variable was performed and adjusted for potential covariates.

Results Participants with MACE had higher 24HUNa levels and RA proportion than those without MACE $(p<0.001)$. The association of MACE with 24HUNa was $\mathrm{J}$-shaped with a gradual increase from about $3 \mathrm{~g} /$ day. The highest 24HUNa ( $\geq 6 \mathrm{~g} /$ day) group was significantly associated with increased prevalence of MACE compared with the reference group (3-3.999 $\mathrm{g} / \mathrm{day})$ after adjusting for all associated covariates (OR 6.75, 95\% $\mathrm{Cl} 1.421$ to 32.039). In the multivariate logistic regression analysis, RA (OR 2.05, 95\% Cl 1.283 to 3.264) and the highest 24HUNa group (OR $6.35,95 \% \mathrm{Cl} 1.337$ to 30.147 ) were significantly associated with MACE even after adjusting for baseline covariates.

Conclusions These nationally representative data suggest that RA and extremely high sodium intake are associated with MACE in the general adult Korean population. Avoiding extremely high salt intake and considering RA as an important risk factor for MACE might help promote public cardiovascular health.
Strengths and limitations of this study

- This study analysed the association of sodium intake and rheumatoid arthritis (RA) conjointly with major adverse cardiovascular events (MACE) using nationally representative samples of the Korean adult population.

- The study used the most recently provided dataset to reflect modern dietary patterns.

- A causal relationship could not be determined owing to the cross-sectional design of this study and participants with pre-existing MACE could have changed their dietary patterns to reduce salt intake.

- This study was unable to get information on disease activity of RA as well as the use of medications that may have affected urinary sodium excretion and definitions of main diseases were based on selfreported questionnaires.

- Analysis on the association between combined status with RA and urinary sodium excretion and MACE was unfeasible owing to the small, unweighted sample size.

\section{INTRODUCTION}

The global burden of cardiovascular diseases (CVD) has risen steadily over the last three decades, and CVD has been the second leading cause of death, accounting for approximately $20 \%$ of all deaths, in Korea. ${ }^{12}$ Therefore, it is important to monitor and manage risk factors for CVD. High salt intake is a well-known risk factor for hypertension. A positive association has been shown between salt intake and blood pressure and decreased dietary salt intake can reduce blood pressure. ${ }^{34}$ The PURE study, a large-scaled global study on the relationship between dietary sodium intake and human health, has reported that positive relationship between sodium intake and blood pressure was steeper at a level of urinary sodium excretion of $>5 \mathrm{~g} /$ day. $^{5}$ However, the association 
between sodium intake and major adverse cardiovascular events (MACE) remains controversial, because the previous studies have reported heterogeneous (linear, J-shaped or U-shaped) associations. ${ }^{6-10}$ The association between salt intake and MACE may vary depending on the characteristics of the study population, such as ethnicity, age distribution and dietary pattern. A recent meta-analysis showed that the effect of reducing sodium intake on blood pressure might be greater in Black and Asian populations. ${ }^{11}$ Mente et al showed that the impact of high urinary sodium excretion on cardiovascular events differed between the populations with and without hypertension. ${ }^{12}$ Therefore, whether high sodium intake is an independent risk factor for MACE requires further investigation.

Rheumatoid arthritis (RA), which is one of the most common inflammatory arthritides in adults, is reportedly associated with an increased cardiovascular risk, to a similar extent as type 2 diabetes mellitus (DM). ${ }^{13} 14$ The increased cardiovascular risk in RA has been largely attributed to the systemic inflammation of RA disease activity and premature atherosclerosis. ${ }^{15-17}$ Several studies in Western populations reported a 1.5- to 2-fold increased risk of cardiovascular morbidity and mortality in patients with RA compared with individuals without RA. ${ }^{18-20} \mathrm{~A}$ similar association was found in a Chinese study, showing approximately twice the risk of MACE in patients with RA than in those with osteoarthritis. ${ }^{21} \mathrm{~A}$ few studies evaluated the association between RA and CVD among the Korean population. Rhew reported that RA was associated with ischaemic heart disease (OR $1.75,95 \%$ CI 1.73 to 1.77 ) and cerebral infarction (OR $1.28,95 \%$ CI 1.26 to 1.30 ) from the data of the Korean Health Insurance Review and Assessment Service. ${ }^{22}$ Jeong et al showed that RA was associated with an increased prevalence of myocardial infarction or angina (OR 1.86, 95\% CI 1.17 to 2.96) using data from the Korean National Health and Nutrition Examination Survey (KNHANES) 2010-2012. ${ }^{23}$ So far, several studies have evaluated the relationship between certain risk factors and MACE from the KNHANES dataset; however most did not include RA as a potential risk factor. ${ }^{23} 24$

Hence, it is necessary to evaluate the association of these potential risk factor-sodium intake and RAwith MACE in addition to the traditional risk factors in the Korean population. The purpose of this study was to evaluate the relationship of MACE with 24-hour urinary sodium excretion (24HUNa), as a surrogate marker of dietary sodium intake, and RA in the Korean adult population using data from the KNHANES.

\section{MATERIALS AND METHODS}

\section{Study design and population}

The KNHANES is an annual nationwide survey of the Korean population, conducted by the Korea Centers for Disease Control and Prevention (CDC) with the approval of the Institutional Review Board of the Korean
CDC. Participants were selected using the proportional allocation-systemic sampling method with multistage stratification to derive a representative Korean population. Voluntary participants, who provided written informed consents, were included in the KNHANES. The survey was conducted by special research teams that completed 1 month of education and practices and whose research ability was verified through regular education and onsite quality management. The KNHANES data were anonymised and released to researchers and are publicly available (http://knhanes.cdc.go.kr).

This study used data from the KNHANES VII (20162018) survey. Among a total of 24269 participants, we included adults aged 20 years or older. We excluded participants with implausible data on daily energy intake $(<500 \mathrm{kcal}$ or $>5000 \mathrm{kcal})$, as in previous studies. ${ }^{25} 26$ Participants diagnosed with liver cirrhosis, cancer and renal insufficiency and those with a serum creatine concentration $\geq 2.0 \mathrm{mg} / \mathrm{dL}$ or missing urinary sodium data were excluded. After applying the exclusion criteria, 13464 participants (weighted $n=90425889$ ) were finally included in our analyses (figure 1).

\section{Covariates and definition of variables}

The data on participants' age, sex, region of residence, income, education and smoking status were collected. Body mass index (BMI) was calculated as weight $(\mathrm{kg})$ divided by the height squared $(\mathrm{m})$. Income status was categorised into four groups (low/mid-low/mid-high/ high) according to the quartiles of the average individual monthly income. Regions of residence were classified by the administrative district. Alcohol consumption was categorised into the following four groups based on the frequency of alcohol consumption during the past year: (1) never, (2) $\leq 1$ time/month, (3), 2-4 times/ month and $(4) \geq 1 /$ week. Information on comorbidities, family history, blood and urine laboratory test results, and variables from nutritional questionnaires were also collected. We defined MACE as a composite of selfreported physician-diagnosed myocardial infarction, angina pectoris, stroke, or a combination of these. Other disease conditions including RA, depression, hypertension, dyslipidaemia and DM were also defined based on self-reported physician diagnosis.

\section{Estimating the 24HUNa}

The KNHANES dataset provided sodium intake, which was estimated using the 24-hour diet recall questionnaire and morning spot urine sodium. The 24-hour diet recall method was reported to inaccurately reflect and underestimate the $24 \mathrm{HUNa}{ }^{27}{ }^{28}$ The formula for estimating the 24HUNa using a single morning fasting urine, as suggested by Tanaka, ${ }^{29}$ strongly correlates with the measured 24HUNa from 24-hour urine collection sample. ${ }^{30}$ It is also suggested as a valid and simple tool to estimate sodium intakes in a large population study as a better alternative to the 24-hour urine collection method. ${ }^{31}{ }^{32}$ Hence, we used the estimated 24HUNa as 


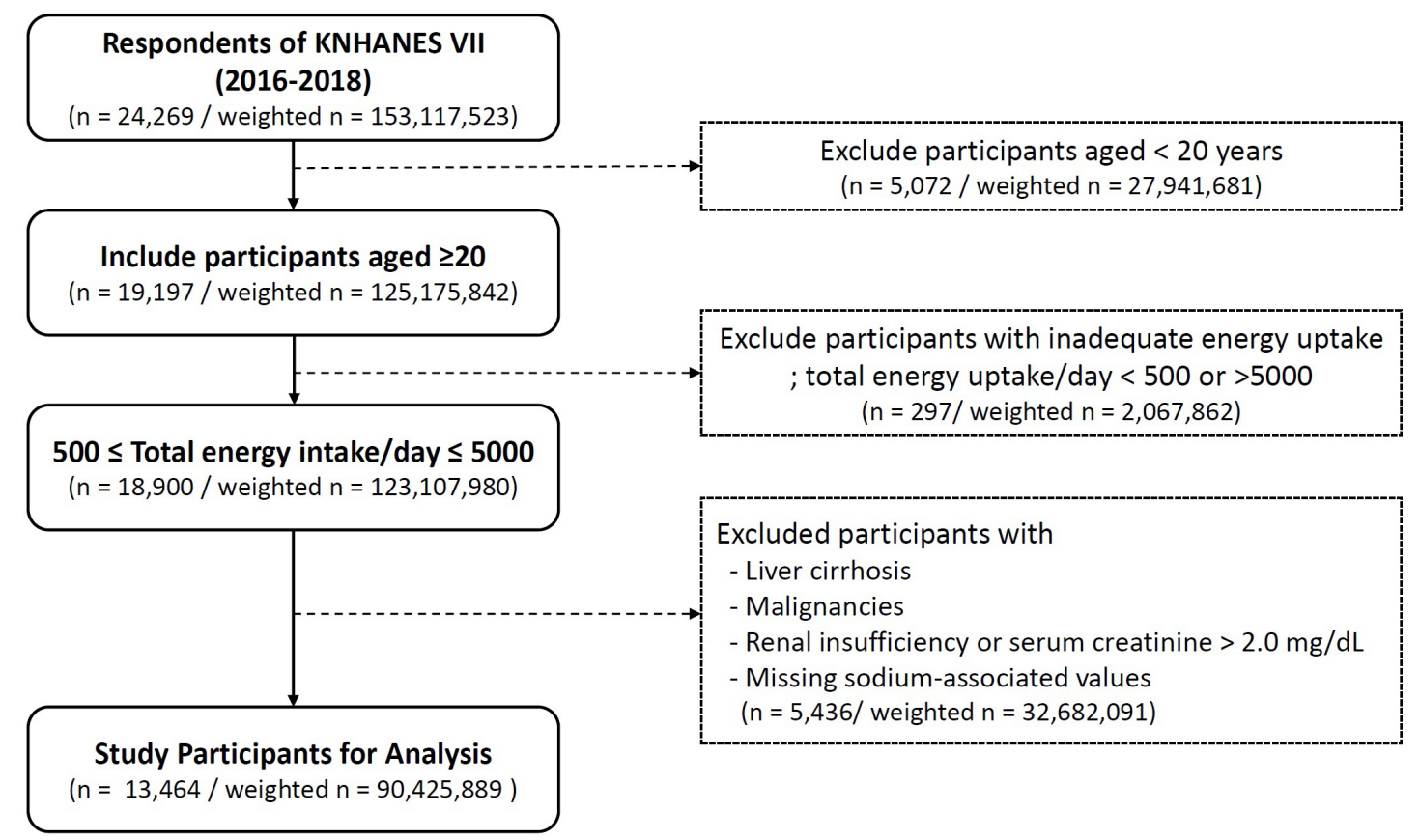

Figure 1 Flow chart showing inclusion and exclusion of subjects according to study design. KNHANES, Korean National Health and Nutrition Examination Survey.

a surrogate marker of dietary sodium intake. It can be calculated using weight, height, age, and measured spot urine creatinine $(\mathrm{Cr})$ and natrium provided from the KNHANES dataset. The estimated $24 \mathrm{HUNa}(\mathrm{mg} /$ day) is considered to reflect equivalently dietary sodium intake $(\mathrm{mg} /$ day) and the equation is as follows:

Estimated 24-hour urinary $\mathrm{Cr}(\mathrm{mg})=(14.89 \times$ [weight $(\mathrm{kg})]+16.14 \times$ [height $(\mathrm{cm})]$ ) $-2.04 \times$ Age -2244.45

Estimated $24 \mathrm{HUNa}(\mathrm{mg} /$ day $)=23 \times 21.98 \times($ [spot urine $\mathrm{Na}(\mathrm{mmol} / \mathrm{L}) /$ spot $\mathrm{Cr}(\mathrm{mg} / \mathrm{dL}) \times 10] \times$ estimated 24-hour urinary $\mathrm{Cr}(\mathrm{mg}))^{0.392}$

\section{Statistical analyses}

The KNHANES used a stratified, multistage, probabilitysampling design to represent the entire population; thus, complex samples analysis procedures using sampling weights were performed. A complex sample plan file was designed to apply the $\mathrm{k}$ strata, primary sample units, and proper usage of sampling weight values. Data are expressed as the absolute number or estimated percentage $(\%)$ or mean \pm SE. The $\chi^{2}$ test and the t-test were performed to analyse the differences between participants with and without MACE and participants with and without RA. Simple linear regression analyses were used to determine the relationships of a single variable with MACE as dependent variable. Restricted cubic spline (RCS) plots were used to explore the shape of the association between 24HUNa and MACE. Participants were divided into five groups according to $24 \mathrm{HUNa}$ as follows: low $(<3 \mathrm{~g})$, reference (3-3.999 g), moderate (4-4.999 g), high (5-5.999 g) and extremely high ( $\geq 6 \mathrm{~g})$. We selected 3-3.999 g/day as the reference range for $24 \mathrm{HUNa}$ based on the trends for MACE in the RCS plot. To determine the association between 24HUNa groups and MACE, we performed multiple logistic regression analyses using three different sequential models: adjusted for age and sex (model 1), further adjusted for total energy intake, BMI, income, education, region of residence, smoking, and family history of MACE (model 2), and adjusted for variables in model 2 and comorbid diseases including hypertension, dyslipidaemia, DM, RA and depression (model 3) in order to explore whether there is a difference when conventional risk comorbidities are included in addition to individual demographic and socioeconomic characteristics. Finally, we used multivariate complex sample logistic regression analysis to identify factors related to MACE, designating all significant covariates, including $24 \mathrm{HUNa}$ in two ways; (1) extremely high $24 \mathrm{HUNa}$ as a dichotomous variable, (2) five 24HUNa groups as a categorical variable. For the subgroup analysis, the same procedures using coronary artery diseases (myocardial infarction or angina) and cerebrovascular disease (stroke) as dependent variables were conducted. We considered a $p<0.05$ as statistically significant. Statistical analysis was conducted using SPSS for Windows, V.25 (IBM) and R V.4.0.2 (R Foundation for Statistical Computing, Vienna, Austria).

\section{Patient and public involvement}

The study population was not involved in the design of the study.

\section{RESULTS}

Comparisons between participants with and without MACE

The prevalence of MACE was 3.7\% among the Korean adult population (table 1). Participants with MACE were older, predominantly men, residents of more rural areas, and more likely to be smokers and non-drinkers than 
Table 1 Comparisons of characteristics according to the presence of MACE among the general Korean population included in the analyses

\begin{tabular}{|c|c|c|c|}
\hline Variables & With MACE $(3.7 \%)$ & $\begin{array}{l}\text { Without MACE } \\
(96.3 \%)\end{array}$ & P value* \\
\hline Unweighted, n & 676 & 12788 & \\
\hline Weighted, $n$ & 3349365 & 87076524 & \\
\hline Age (years) & $66.2 \pm 0.5$ & $46.8 \pm 0.3$ & $<0.001$ \\
\hline \multicolumn{4}{|l|}{ Age group } \\
\hline $20-49$ & $316672(7.0)$ & $68910214(32.4)$ & $<0.001$ \\
\hline $50-59$ & 874425 (19.3) & 24310692 (16.4) & \\
\hline $60-69$ & 1330644 (29.3) & $15082772(10.2)$ & \\
\hline$\geq 70$ & 2020659 (44.5) & 12329764 (8.3) & \\
\hline Sex & & & $<0.001$ \\
\hline Men & 1943927 (58.0) & 43082845 (49.5) & \\
\hline Women & 1205437 (42.0) & $43993678(50.5)$ & \\
\hline $\begin{array}{l}\text { Region of } \\
\text { residence }\end{array}$ & & & 0.002 \\
\hline Metropolitan & 1506804 (45.0) & 40135796 (46.1) & \\
\hline Urban & 1150887 (34.4) & $34134283(39.2)$ & \\
\hline Rural & $691672(20.7)$ & $12806444(14.7)$ & \\
\hline $\begin{array}{l}\text { Body mass index } \\
\left(\mathrm{kg} / \mathrm{m}^{2}\right)\end{array}$ & $24.61 \pm 0.14$ & $23.95 \pm 0.04$ & $<0.001$ \\
\hline Income & & & $<0.001$ \\
\hline Low & 1188254 (35.6) & 12706743 (14.6) & \\
\hline Mid-low & 853342 (25.6) & 20380006 (23.5) & \\
\hline Mid-high & 765434 (22.9) & 25502441 (29.4) & \\
\hline High & 61729 (15.9) & 28253096 (32.5) & \\
\hline Education & & & $<0.001$ \\
\hline$\leq$ Elementary & $1424388(42.7)$ & 11891195 (13.7) & \\
\hline Middlehigh & 1409969 (42.3) & 37048942 (42.6) & \\
\hline$\geq$ College & $501740(15.0)$ & $37962690(43.7)$ & \\
\hline Smoking & & & $<0.001$ \\
\hline Never-smoker & $1579384(47.2)$ & $50517035(58.1)$ & \\
\hline Ex-smoker & 1206389 (36.0) & $18584453(21.4)$ & \\
\hline Current smoker & 563590 (16.8) & $17812544(20.5)$ & \\
\hline $\begin{array}{l}\text { Alcohol } \\
\text { consumption }\end{array}$ & & & $<0.001$ \\
\hline Never & 1226155 (36.6) & 19170781 (22.0) & \\
\hline$\leq 1$ month & 846037 (25.3) & 24888864 (28.6) & \\
\hline $2-4 /$ month & $470455(14.0)$ & $21869824(25.2)$ & \\
\hline 1>week & 806718 (24.1) & $21015283(24.2)$ & \\
\hline \multicolumn{4}{|l|}{ Comorbidities } \\
\hline Hypertension & 2115091 (63.1) & 15576157 (17.9) & $<0.001$ \\
\hline Dyslipidaemia & 1898258 (41.8) & 17540299 (11.8) & $<0.001$ \\
\hline $\begin{array}{l}\text { Diabetes } \\
\text { mellitus }\end{array}$ & 945135 (28.2) & 5693892 (6.5) & $<0.001$ \\
\hline Depression & 337066 (10.1) & 3338335 (3.8) & $<0.001$ \\
\hline $\begin{array}{l}\text { Rheumatoid } \\
\text { arthritis }\end{array}$ & $34692(5.2)$ & 96004 (1.5) & $<0.001$ \\
\hline $\begin{array}{l}\text { Family history of } \\
\text { MACE }\end{array}$ & 75337 (2.2) & $97548(1.1)$ & 0.013 \\
\hline $\begin{array}{l}\text { Total energy intake } \\
\text { (kcal/day) }\end{array}$ & $1726.7 \pm 35.8$ & $2045.0 \pm 12.4$ & $<0.001$ \\
\hline
\end{tabular}

Continued

\begin{tabular}{llll}
\hline Table 1 & Continued & & \\
Variables & With MACE (3.7\%) & $\begin{array}{l}\text { Without MACE } \\
\mathbf{( 9 6 . 3 \% )}\end{array}$ & P value* $^{*}$ \\
\hline Unweighted, $\mathbf{n}$ & $\mathbf{6 7 6}$ & $\mathbf{1 2 7 8 8}$ & \\
\hline Weighted, $\mathbf{n}$ & $\mathbf{3 3 4 9 3 6 5}$ & $\mathbf{8 7 0 7 6 5 2 4}$ & \\
\hline $\begin{array}{l}\text { Estimated 24-hour } \\
\text { urinary sodium } \\
\text { excretion (g/d) }\end{array}$ & $3.299 \pm 0.040$ & $3.070 \pm 0.001$ & $<0.001$ \\
\end{tabular}

Values are presented as mean $\pm \mathrm{SD}$ or number $(\%)$.

"P values were obtained by $\chi^{2}$ test or t-test

MACE, major adverse cardiovascular events.

those without MACE. They had lower socioeconomic status, higher BMI and more comorbidities including hypertension, dyslipidaemia, DM, depression and RA (5.2\% in MACE vs $1.5 \%$ in non-MACE, $\mathrm{p}<0.001)$. Daily total energy intake was lower in patients with MACE, while 24HUNa estimated using the Tanaka formula was significantly higher $(3.229 \pm 0.040$ vs $3.070 \pm 0.001, \mathrm{p}<0.001)$.

The prevalence of self-reported RA was $1.7 \%$ among the included adults. We also compared the characteristics of Korean adults stratified by RA (online supplemental table $1)$. They also had more comorbidities including hypertension, dyslipidaemia, DM and depression. The prevalence of MACE was significantly high in patients with RA ( $11.5 \%$ in RA vs $3.6 \%$ in non-RA, $\mathrm{p}<0.001)$. Whereas the total energy intake was lower in patients with RA than in those without RA, 24HUNa estimated using the Tanaka equation was higher.

\section{Frequency distribution of 24HUNa groups and its relation to MACE}

The frequency distribution of 24HUNa groups is shown in (online supplemental figure 1). The number of participants in the $<3$ g group was the highest. We drew RCS plots to determine the relevant pattern of $24 \mathrm{HUNa}$ and MACE, as shown in figure 2. The ORs for MACE gradually increased at a $24 \mathrm{HUNa} \geq 3 \mathrm{~g}$; therefore, we set the $3-4 \mathrm{~g}$ group as the reference group in the subsequent analyses.

\section{Factors related to the presence of MACE}

In the unadjusted regression analyses, older age, male sex, rural residence, higher BMI, low socioeconomic status and non-drinking showed significant associations with the presence of MACE. Comorbidities such as RA, hypertension, dyslipidaemia, DM and depression, and family history of MACE were also significantly associated with the presence of MACE. Total energy intake (OR 0.99, $95 \%$ CI 0.994 to $0.997, \mathrm{p}<0.001$ ) was negatively associated with MACE, whereas the estimated $24 \mathrm{HUNa}$ showed positive associations with MACE (OR $1.43,95 \%$ CI 1.274 to $1.597, \mathrm{p}<0.001$, table 2 ). The group with extremely high $24 \mathrm{HUNa}(\geq 6 \mathrm{~g} /$ day $)$ was significantly associated with an increased risk of MACE.

Next, to explore the elaborate relationship between 24HUNa levels and the presence of MACE, we performed multiple regression analyses using sequential adjustment models (table 3). The highest $24 \mathrm{HUNa}$ subgroup ( $\geq 6 \mathrm{~g}$ / 


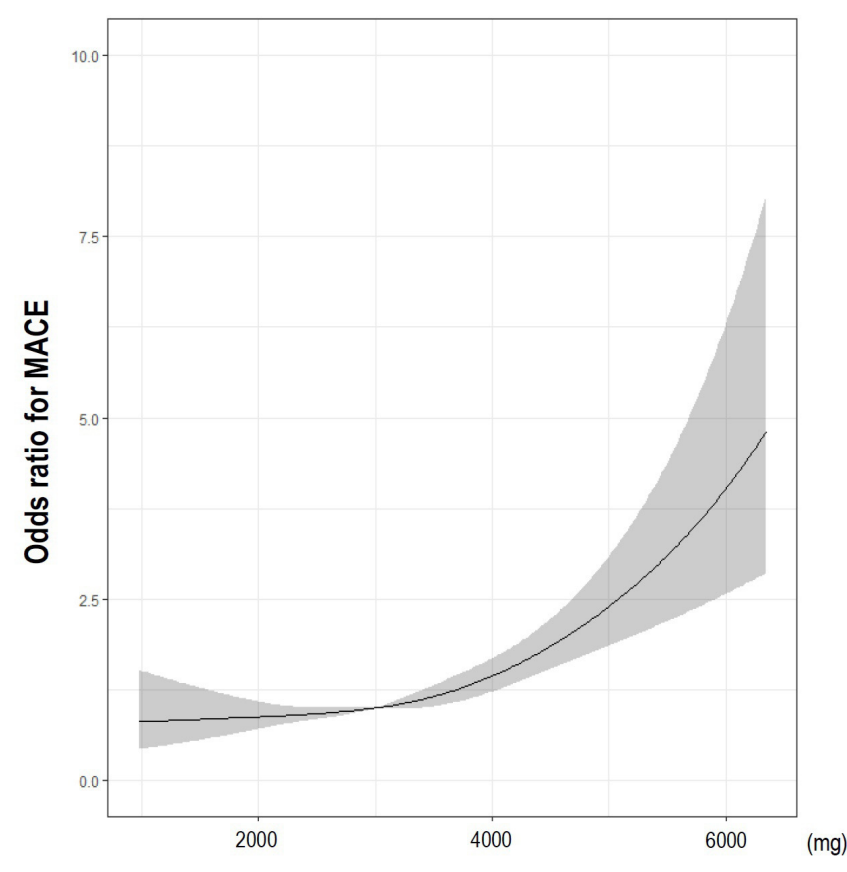

24-hour urinary sodium excretion estimated using the Tanaka equation

Figure 2 Restricted cubic spline plots showing the association between the estimated 24-hour urinary sodium excretion and the presence of major cardiovascular events. MACE, major adverse cardiovascular events.

day) was more likely to have MACE than the reference group (3-4 g/day) in models 1, 2 and 3 (OR 6.75, 95\% CI 1.421 to 32.039 in model 3 ).

To determine independent risk factors for MACE, multivariate logistic regression analyses were performed including all significant variables. As presented in table 4, old age, male sex, low educational level, ex-smoker, comorbidities such as RA (OR 2.05, 95\% CI 1.283 to 3.264, $\mathrm{p}=0.003$ ), hypertension (OR 2.15, 95\% CI 1.683 to 2.739, $\mathrm{p}<0.001$ ), dyslipidaemia (OR 1.55, 95\% CI 1.252 to $1.919, \mathrm{p}<0.001$ ), DM (OR $1.63,95 \%$ CI 1.287 to 2.072 , $\mathrm{p}<0.001)$ and depression, low total energy intake and the group with extremely high 24HUNa (OR 6.35, 95\% CI 1.337 to $30.147, \mathrm{p}=0.02$ ) were significantly associated with the presence of MACE. When 24HUNa was adopted as five-category groups, the results were similar to those from the aforementioned analyses, and the highest $24 \mathrm{HUNa}$ group was significantly associated with the presence of MACE compared with the reference group (3-3.999 g/ day) (online supplemental table 2). In the subgroup analyses on coronary artery disease and cerebrovascular disease as separate dependent variables, both RA and the group with extremely high 24HUNa were significantly associated with coronary artery disease, whereas their association with cerebrovascular disease was insignificant (online supplemental tables 3 and 4).

\section{DISCUSSION}

Using nationally representative data, we investigated the relationship of RA and estimated $24 \mathrm{HUNa}$ with MACE
Table 2 Simple logistic regression analyses to determine the associated factors for MACE

\begin{tabular}{|c|c|c|c|}
\hline Variables & & OR $(95 \% \mathrm{Cl})$ & P value* \\
\hline Age (years) & & 1.01 (1.082 to 1.097$)$ & $<0.001$ \\
\hline \multirow[t]{4}{*}{ Age group } & $20-49$ & Ref & \\
\hline & $50-59$ & 6.65 (4.246 to 10.410$)$ & $<0.001$ \\
\hline & $60-69$ & 16.30 (10.537 to 25.206$)$ & $<0.001$ \\
\hline & $\geq 70$ & 33.33 (22.036 to 50.407$)$ & $<0.001$ \\
\hline \multirow[t]{2}{*}{ Sex } & Men & Ref & \\
\hline & Women & 0.71 (0.598 to 0.838$)$ & $<0.001$ \\
\hline \multirow{3}{*}{$\begin{array}{l}\text { Region of } \\
\text { residence }\end{array}$} & Metropolitan & Ref & \\
\hline & Urban & $0.90(0.725$ to 1.112$)$ & 0.005 \\
\hline & Rural & 1.44 (1.115 to 1.856$)$ & $<0.001$ \\
\hline $\begin{array}{l}\text { Body mass } \\
\text { index }\left(\mathrm{kg} / \mathrm{m}^{2}\right)\end{array}$ & & 1.05 (1.029 to 1.069$)$ & $<0.001$ \\
\hline \multirow[t]{4}{*}{ Income } & High & Ref & \\
\hline & Mid-high & 1.60 (1.197 to 2.135$)$ & 0.002 \\
\hline & Mid-low & 2.23 (1.684 to 2.952$)$ & $<0.001$ \\
\hline & Low & 4.98 (3.813 to 6.504$)$ & $<0.001$ \\
\hline \multirow[t]{3}{*}{ Education } & $\geq$ College & Ref & \\
\hline & Middle-high & 2.88 (2.159 to 3.840$)$ & $<0.001$ \\
\hline & $\leq$ Elementary & 9.06 (6.871 to 11.956$)$ & $<0.001$ \\
\hline \multirow[t]{3}{*}{ Smoking } & Never-smoker & Ref & \\
\hline & Ex-smoker & 2.08 (1.701 to 2.534$)$ & $<0.001$ \\
\hline & Current smoker & 1.01 (0.780 to 1.312$)$ & 0.928 \\
\hline \multirow{4}{*}{$\begin{array}{l}\text { Alcohol } \\
\text { consumption }\end{array}$} & Never & Ref & \\
\hline & $\leq 1$ month & $0.53(0.415$ to 0.681$)$ & $<0.001$ \\
\hline & $2-4 /$ month & $0.34(0.258$ to 0.438$)$ & $<0.001$ \\
\hline & $1>$ week & $0.60(0.466$ to 0.773$)$ & $<0.001$ \\
\hline \multicolumn{4}{|l|}{ Comorbidities } \\
\hline \multirow{2}{*}{$\begin{array}{l}\text { Rheumatoid } \\
\text { arthritis }\end{array}$} & No & Ref & \\
\hline & Yes & 3.50 (2.269 to 5.391$)$ & $<0.001$ \\
\hline \multirow[t]{2}{*}{ Hypertension } & No & Ref & \\
\hline & Yes & 7.87 (6.527 to 9.481$)$ & $<0.001$ \\
\hline \multirow[t]{2}{*}{ Dyslipidaemia } & No & Ref & \\
\hline & Yes & 4.24 (3.531 to 5.099$)$ & $<0.001$ \\
\hline \multirow{2}{*}{$\begin{array}{l}\text { Diabetes } \\
\text { mellitus }\end{array}$} & No & Ref & \\
\hline & Yes & 5.62 (4.584 to 6.888$)$ & $<0.001$ \\
\hline \multirow[t]{2}{*}{ Depression } & No & Ref & \\
\hline & Yes & 2.81 (2.082 to 3.783 ) & $<0.001$ \\
\hline \multirow{2}{*}{$\begin{array}{l}\text { Family history } \\
\text { of MACE }\end{array}$} & No & Ref & \\
\hline & Yes & 2.13 (1.156 to 3.909$)$ & 0.015 \\
\hline $\begin{array}{l}\text { Total energy } \\
\text { intake (kcal/d) }\end{array}$ & & $0.99(0.994$ to 0.997$)$ & $<0.001$ \\
\hline $24 \mathrm{HUNa}(\mathrm{g} / \mathrm{d})$ & & $1.43(1.274$ to 1.597$)$ & $<0.001$ \\
\hline \multirow{2}{*}{$\begin{array}{l}\text { Group with } \\
\text { extremely } \\
\text { high } 24 \mathrm{HUNa} \\
\text { ( } 24 \mathrm{HUNa} \geq 6 \\
\text { g/day) }\end{array}$} & No & Ref & \\
\hline & Yes & 18.41 (5.863 to 57.773$)$ & $<0.001$ \\
\hline
\end{tabular}

${ }^{*} \mathrm{P}$ values from simple logistic regression with MACE as dependent variable.

24HUNa, estimated 24-hour urinary sodium excretion; MACE, major adverse cardiovascular events; Ref, reference. 
Table 3 Logistic regression analyses to determine the association between estimated urinary sodium excretion groups and major adverse cardiovascular events

\begin{tabular}{|c|c|c|c|c|c|}
\hline $\begin{array}{l}\text { Estimated } 24 \text {-hour urinary sodium } \\
\text { excretion using Tanaka equation }\end{array}$ & $<3 \mathrm{~g}$ & $3-3.999 \mathrm{~g}$ & $4-4.999 \mathrm{~g}$ & $5-5.999 \mathrm{~g}$ & $\geq 6 \mathrm{~g}$ \\
\hline Unweighted no & 6166 & 5537 & 1528 & 182 & 15 \\
\hline Unweighted no of MACE & 254 & 278 & 117 & 16 & 6 \\
\hline Weighted no & 42953228 & 36493867 & 9580096 & 1087154 & 80517 \\
\hline Weighted no of MACE & 1273626 & 1373922 & 559434 & 70641 & 33006 \\
\hline Univariate & $0.78(0.638-0.957)$ & ref & $1.56^{*}(1.206-2.083)$ & $1.78(0.920-3.431)$ & $17.76^{\star}(5.635-55.963)$ \\
\hline Model 1† & $1.11(0.901-1.365)$ & ref & $1.33^{*}(1.006-1.755)$ & $1.12(0.538-2.326)$ & $11.64^{*}(2.340-57.931)$ \\
\hline Model $2 \ddagger$ & $1.13(0.916-1.394)$ & ref & $1.33(1.000-1.765)$ & $1.04(0.486-2.234)$ & $8.68^{*}(1.846-40.827)$ \\
\hline Model 3§ & $1.06(0.857-1.314)$ & ref & $1.27(0.952-1.701)$ & $1.02(0.478-2.164)$ & $6.75^{\star}(1.421-32.039)$ \\
\hline
\end{tabular}

Values are in OR (95\% Cls).

${ }^{*} \mathrm{P}<0.05, \mathrm{p}$ values from univariate and multivariable logistic regression with MACE as dependent variable.

†Model 1 adjusted for age, sex.

¥Model 2 further adjusted for total energy intake, body mass index, income, education, region of residence, smoking, alcohol consumption, family history of MACE.

§Model 3 adjusted for factors in model 2 and rheumatoid arthritis, depression, hypertension, dyslipidaemia, diabetes mellitus. MACE, major adverse cardiovascular events.

simultaneously in the Korean adult population. The highest risk for MACE was seen in those with extremely high estimated $24 \mathrm{HUNa}$ ( $\geq 6 \mathrm{~g} /$ day), even after adjusting for traditional comorbidities including hypertension, dyslipidaemia and DM. Multivariate logistic regression analysis demonstrated that RA and extremely high estimated 24HUNa were significantly associated with the presence of MACE.

In our study, MACE was prominent among aged men. Although smoking is a well-known risk factor for MACE, in this study, only the proportion of ex-smokers in the MACE group was higher than that in the non-MACE group. This can be explained by the fact that a substantial number of MACE patients may have discontinued smoking on medical advice after diagnosis of MACE. In participants with MACE, estimated 24HUNa using the Tanaka formula was significantly higher despite lower energy intake than in those without MACE. As expected, participants with MACE showed significantly higher prevalence of RA, depression, hypertension, DM and dyslipidaemia. Patients with RA also had more comorbidities such as hypertension, dyslipidaemia, DM, MACE and depression, as previous studies have confirmed. ${ }^{334}$

After adjusting for all associated covariates, RA was still an associated risk factor for MACE with an OR of approximately 2. These results were consistent with those of previously reported studies that demonstrated an approximately 2-fold increased risk for cardiovascular events among Western populations. ${ }^{185}$ A recent study by Jeong et al using the 2010-2012 KNHANES data reported an increased risk for myocardial infarction or angina (OR 1.86, 95\% CI 1.17 to 2.96) in patients with RA; however, their analyses were not adjusted for traditional cardiovascular risk factors such as hypertension and DM. ${ }^{33}$ Subsequently, Lee $e t a l^{36}$ showed an increased prevalence of coronary artery diseases (OR 2.97, 95\% CI 1.15 to 7.68 ) using propensity-score matching from the KNHANES 2008-2012 data; however, they only considered coronary artery disease.

In this study, the continuous value of the estimated 24HUNa showed significant positive associations with the presence of MACE (OR 1.43, 95\% CI 1.274 to 1.597) in the simple regression analyses. However, RCS plots noted a J-shaped association between estimated $24 \mathrm{HUNa}$ and the presence of MACE in our population, rather than a linear positive association. Hence, we classified estimated 24HUNa into five groups with ranges of $1 \mathrm{~g}$, as did previous Western studies. ${ }^{712}$ In those studies, the criterion for extremely high urinary sodium excretion was set to $\geq 7 \mathrm{~g} /$ day. Because few participants belonged to the $\geq 7 \mathrm{~g}$ /day group in our population, we designated $\geq 6 \mathrm{~g} /$ day as the extremely high group. In addition, we selected 3-4 g/day as the reference range for sodium intake based on the trends for MACE in the RCS plots. This range corresponds to the recently reported mean sodium intake among the Korean adult population. ${ }^{37}$ A recent pooled analysis, which identified a U-shaped association between CVD and sodium excretion, found that an estimated sodium excretion between 4 and $5 \mathrm{~g}$ /day led to the lowest risk of CVD. This difference is attributed to the fact that salt intake by Koreans is still higher than that prescribed by the $\mathrm{WHO}$ guidelines ( $\leq 2 \mathrm{~g} /$ day) but less than observed in Western countries.

High dietary sodium intake is associated with high morbidity and mortality, which is predominantly mediated by its harmful effect on blood pressure in the general population. ${ }^{38}$ Many epidemiological and prospective cohort studies have investigated the association between urinary sodium excretion and CVD events and mortality; however, the relationship has not been resolved. Some studies suggested a positive association between high sodium intake and higher risk of CVD events, ${ }^{39}{ }^{40}$ whereas other research reported a U-shaped or J-shaped association, with an increased risk at 
Table 4 Multivariable logistic regression analysis to determine independently associated factors for the presence of MACE

\begin{tabular}{|c|c|c|c|c|}
\hline Variables & & OR & $95 \% \mathrm{Cl}$ & P value* \\
\hline \multirow[t]{4}{*}{ Age group } & $20-49$ & Ref & & \\
\hline & $50-59$ & 4.41 & 2.677 to 7.258 & $<0.001$ \\
\hline & $60-69$ & 7.43 & 4.322 to 12.784 & $<0.001$ \\
\hline & $\geq 70$ & 12.53 & 7.041 to 22.313 & $<0.001$ \\
\hline \multirow[t]{2}{*}{ Sex } & Men & Ref & & \\
\hline & Women & 0.50 & 0.369 to 0.690 & $<0.001$ \\
\hline \multirow{3}{*}{$\begin{array}{l}\text { Region of } \\
\text { residence }\end{array}$} & Metropolitan & Ref & & \\
\hline & Urban & 0.94 & 0.752 to 1.184 & 0.629 \\
\hline & Rural & 0.94 & 0.729 to 1.211 & 0.973 \\
\hline $\begin{array}{l}\text { Body mass index } \\
\left(\mathrm{kg} / \mathrm{m}^{2}\right)\end{array}$ & & 1.01 & 0.978 to 1.034 & 0.701 \\
\hline \multirow[t]{4}{*}{ Income } & Low & Ref & & \\
\hline & Mid-low & 1.03 & 0.786 to 1.345 & 0.199 \\
\hline & Mid-high & 1.18 & 0.875 to 1.598 & 0.123 \\
\hline & High & 0.80 & 0.573 to 1.123 & 0.012 \\
\hline \multirow[t]{3}{*}{ Education } & $\geq$ College & Ref & & \\
\hline & Middle-High & 1.54 & 1.094 to 2.176 & 0.013 \\
\hline & $\leq$ Elementary & 1.41 & 1.035 to 1.923 & 0.030 \\
\hline \multirow[t]{3}{*}{ Smoking } & Never-smoker & Ref & & \\
\hline & Ex-smoker & 1.54 & 1.121 to 2.117 & 0.130 \\
\hline & $\begin{array}{l}\text { Current } \\
\text { smoker }\end{array}$ & 1.32 & 0.922 to 1.875 & 0.323 \\
\hline \multirow{4}{*}{$\begin{array}{l}\text { Alcohol } \\
\text { consumption }\end{array}$} & Never & Ref & & \\
\hline & $\leq 1$ month & 1.16 & 0.890 to 1.517 & 0.939 \\
\hline & $2-4 /$ month & 0.80 & 0.459 to 1.073 & 0.315 \\
\hline & $1 \geq$ week & 0.99 & 0.737 to 1.325 & 0.192 \\
\hline \multicolumn{5}{|l|}{ Comorbidities } \\
\hline \multirow{2}{*}{$\begin{array}{l}\text { Rheumatoid } \\
\text { arthritis }\end{array}$} & No & Ref & & \\
\hline & Yes & 2.05 & 1.283 to 3.264 & 0.003 \\
\hline \multirow[t]{2}{*}{ Hypertension } & No & Ref & & \\
\hline & Yes & 2.15 & 1.693 to 2.739 & $<0.001$ \\
\hline \multirow[t]{2}{*}{ Dyslipidaemia } & No & Ref & & \\
\hline & Yes & 1.55 & 1.252 to 1.919 & $<0.001$ \\
\hline \multirow[t]{2}{*}{ Diabetes mellitus } & No & Ref & & \\
\hline & Yes & 1.63 & 1.287 to 2.072 & $<0.001$ \\
\hline \multirow[t]{2}{*}{ Depression } & No & Ref & & \\
\hline & Yes & 2.26 & 1.594 to 3.190 & $<0.001$ \\
\hline \multirow{2}{*}{$\begin{array}{l}\text { Family history of } \\
\text { MACE }\end{array}$} & No & Ref & & \\
\hline & Yes & 1.99 & 0.998 to 3.974 & 0.051 \\
\hline $\begin{array}{l}\text { Total energy intake } \\
\text { (kcal/day) }\end{array}$ & & 0.75 & 0.631 to 0.880 & 0.001 \\
\hline \multirow{2}{*}{$\begin{array}{l}\text { Group with } \\
\text { extremely high } \\
24 \mathrm{HUNa}(24 \mathrm{HUNa} \\
\geq 6 \text { g/day) }\end{array}$} & No & Ref & & \\
\hline & Yes & 6.35 & 1.337 to 30.147 & 0.020 \\
\hline
\end{tabular}

${ }^{*} \mathrm{P}$ values from multivariable logistic regression with MACE as dependent variable. $24 \mathrm{HUNa}$, 24-hour urinary sodium excretion; MACE, major adverse cardiovascular events. both low and high sodium intake. ${ }^{641}$ However, a subsequent pooled analysis suggested that the association was different depending on hypertension status. ${ }^{12}$ In our multiple model regression analyses of estimated 24HUNa groups, the highest $24 \mathrm{HUNa}$ group $(\geq 6 \mathrm{~g} /$ day) was significantly associated with the presence of MACE after adjustment for well-known socioeconomic and lifestyle risk factors (models 1 and 2). Furthermore, its statistical significance remained even after additional adjustment were made for comorbidities including hypertension, dyslipidaemia, DM, depression, and RA (model 3). These factors were also consistently associated with MACE in the multivariate logistic regression analyses. Therefore, the optimal control of these comorbidities as well as avoidance of extremely high sodium intake will be beneficial to prevent MACE in the adult Korean population.

When extremely high estimated 24HUNa was included as a dichotomous or five-group categorical variable in the multivariate logistic regression analyses, the highest $24 \mathrm{HUNa}$ group was an independent risk factor for MACE (OR 6.35, 95\% CI 1.337 to 30.147 and OR $6.75,95 \%$ CI 1.421 to 32.039 , respectively). In line with these findings, Mente $e t a l^{12}$ also reported that individuals with hypertension consuming $\geq 6 \mathrm{~g}$ / day of sodium had higher risk for CVD and death. Relatively few studies have investigated the association between sodium intake and cardiovascular risk in Asians. It was recently shown that although sodium excretion was correlated with cardiovascular events, statistical significance disappeared after adjusting for hypertension and use of anti-hypertensive medication among the Chinese population. ${ }^{42}$ Another recently published study using the KNHANES data noted a higher risk of CVD-associated mortality in women with top-quartile sodium intake (energy-adjusted sodium intake $>5625 \mathrm{mg}$ / day). ${ }^{43}$ In the subgroup analyses, only the coronary artery disease group showed the same results. Hence, our results for MACE may be mainly attributable to those with coronary artery disease.

Excess salt intake can trigger and/or worsen autoimmune responses. ${ }^{44}$ A recent Japanese study has shown significant association between salt load index (urinary sodium-topotassium ratio) and current disease activity in patients with RA. ${ }^{45}$ Unfortunately, we could not determine a similar relationship owing to the absence of relevant items on disease activity for RA in KNHANES dataset. Besides, since the estimated 24HUNa in the RA group was higher than that in the non-RA group, we attempted to perform a similar multivariate regression analysis confined to the RA population, to confirm whether salt intake affects the presence of MACE particularly in patients with RA. However, the small number of patients with RA (unweighted $n=298$ ) and the events of interest (MACE, unweighted $n=36$ ) limited the logistic regression analysis of only the RA subgroup.

This study had several limitations. First, due to its crosssectional nature, the causal relationship between the variables of interest could not be evaluated. Second, drugs such as antihypertensive agents, metformin and glucocorticoids could affect urinary sodium excretion or MACE. ${ }^{46-48}$ However, we were not able to adjust for them because of the absence of information on medication in the KNHANES dataset. Third, 
since definitions of main diseases were based on self-reported physician-diagnosed status, their prevalence might have been overestimated. Besides, the exclusion of approximately half of the participants could have led to a selection bias. Moreover, participants with MACE risks could have preventively reduced dietary sodium intake. Finally, the gold standard for the assessment of sodium intake is the multiple assessments of $24 \mathrm{HUNa} .{ }^{49}{ }^{50}$ In this study, the Tanaka equation was used to calculate the estimated 24HUNa from spot urine values. Despite these limitations, our study had significant contributions. To the best of our knowledge, we were the first to comprehensively analyse the conjoint association of RA and sodium intake with MACE using representative data of the Korean population. In addition, we approximated the modern dietary pattern by using the most recent dataset and our analyses included the most associated confounders relevant to MACE. Further prospective research with a large sample size is warranted to elucidate firm evidence about the association between sodium intake and cardiovascular risk among the Korean population.

In conclusion, we showed that RA and extremely high sodium intake were independently associated with an increased risk of MACE in the Korean adult population. In addition to the management of traditional risk factors, it is necessary to promote awareness regarding avoidance of extremely high sodium intake and to consider RA as an important risk factor for MACE. Our results could help in the recommendation of a policy for salt reduction policy for the Korean population and patients with RA to achieve potential cardiovascular benefits.

Contributors J-HB contributed to data collection, performed statistical analyses and drafted the initial manuscript. M-YS and EHK collected the data, performed statistical analyses and contributed to the interpretation of data. YJL contributed to the interpretation of data and critically reviewed the data. Y-JH designed the study, performed statistical analyses and critically reviewed the data. Y-JH is the guarantor of the study. All authors have critically revised the manuscript and approved the final version for publication.

Funding This work was supported by the Seoul National University Bundang Hospital Research Fund (grant no. 02-2018-047).

Competing interests None declared.

Patient consent for publication Not applicable.

Ethics approval This study was approved by the Institutional Review Board of Seoul National University Bundang Hospital. Written informed consent was obtained from participants before completing the survey (IRB No. X-1902/524-901).

Provenance and peer review Not commissioned; externally peer reviewed.

Data availability statement Data are available on reasonable request.

Supplemental material This content has been supplied by the author(s). It has not been vetted by BMJ Publishing Group Limited (BMJ) and may not have been peer-reviewed. Any opinions or recommendations discussed are solely those of the author(s) and are not endorsed by BMJ. BMJ disclaims all liability and responsibility arising from any reliance placed on the content. Where the content includes any translated material, BMJ does not warrant the accuracy and reliability of the translations (including but not limited to local regulations, clinical guidelines, terminology, drug names and drug dosages), and is not responsible for any error and/or omissions arising from translation and adaptation or otherwise.

Open access This is an open access article distributed in accordance with the Creative Commons Attribution Non Commercial (CC BY-NC 4.0) license, which permits others to distribute, remix, adapt, build upon this work non-commercially, and license their derivative works on different terms, provided the original work is properly cited, appropriate credit is given, any changes made indicated, and the use is non-commercial. See: http://creativecommons.org/licenses/by-nc/4.0/.

\section{ORCID iDs}

Yun Jong Lee http://orcid.org/0000-0001-7615-8611

You-Jung Ha http://orcid.org/0000-0001-6107-9523

\section{REFERENCES}

1 Korea S. Causes of Death Statistics in 2019 [Internet], 2020. Available: http://kostat.go.kr/portal/eng/pressReleases/8/10/index. board? bmode=read\&bSeq=\&aSeq $=385629 \&$ pageNo=1\&rowNum $=$ 10\&navCount $=10 \&$ currPg $=\&$ searchlnfo $=\&$ sTarget $=$ title\&sTxt $=$

2 Roth GA, Mensah GA, Johnson CO, et al. Global burden of cardiovascular diseases and risk factors, 1990-2019: update from the GBD 2019 study. J Am Coll Cardiol 2020;76:2982-3021.

3 He FJ, Li J, Macgregor GA. Effect of longer term modest salt reduction on blood pressure: cochrane systematic review and metaanalysis of randomised trials. BMJ 2013;346:f1325.

4 Sacks FM, Svetkey LP, Vollmer WM, et al. Effects on blood pressure of reduced dietary sodium and the dietary approaches to stop hypertension (DASH) diet. DASH-Sodium Collaborative Research Group. N Engl J Med 2001;344:3-10.

5 Mente A, O'Donnell MJ, Rangarajan S, et al. Association of urinary sodium and potassium excretion with blood pressure. N Engl J Med 2014;371:601-11.

6 O'Donnell M, Mente A, Rangarajan S, et al. Urinary sodium and potassium excretion, mortality, and cardiovascular events. $N$ Engl J Med 2014;371:612-23.

7 O'Donnell M, Mente A, Rangarajan S, et al. Joint association of urinary sodium and potassium excretion with cardiovascular events and mortality: prospective cohort study. BMJ 2019;364:1772.

8 Taylor RS, Ashton KE, Moxham T, et al. Reduced dietary salt for the prevention of cardiovascular disease: a meta-analysis of randomized controlled trials (cochrane review). Am J Hypertens 2011;24:843-53.

9 Joosten MM, Gansevoort RT, Mukamal KJ, et al. Sodium excretion and risk of developing coronary heart disease. Circulation 2014;129:1121-8.

10 Elliott P, Muller DC, Schneider-Luftman D, et al. Estimated 24-hour urinary sodium excretion and incident cardiovascular disease and mortality among 398628 individuals in UK Biobank. Hypertension 2020;76:683-91.

11 Graudal NA, Hubeck-Graudal T, Jurgens G. Effects of low sodium diet versus high sodium diet on blood pressure, renin, aldosterone, catecholamines, cholesterol, and triglyceride. Cochrane Database Syst Rev 2020;12:CD004022.

12 Mente A, O'Donnell M, Rangarajan S, et al. Associations of urinary sodium excretion with cardiovascular events in individuals with and without hypertension: a pooled analysis of data from four studies. Lancet 2016;388:465-75.

13 Soubrier M, Barber Chamoux N, Tatar Z, et al. Cardiovascular risk in rheumatoid arthritis. Joint Bone Spine 2014;81:298-302.

14 Agca R, Hopman LHGA, Laan KJC, et al. Cardiovascular event risk in rheumatoid arthritis compared with type 2 diabetes: a 15-year longitudinal study. J Rheumatol 2020;47:316-24.

15 Libby P. Role of inflammation in atherosclerosis associated with rheumatoid arthritis. Am J Med 2008;121:S21-31.

16 Myasoedova E, Crowson CS, Kremers HM, et al. Lipid paradox in rheumatoid arthritis: the impact of serum lipid measures and systemic inflammation on the risk of cardiovascular disease. Ann Rheum Dis 2011;70:482-7.

17 Choy E, Ganeshalingam K, Semb AG, et al. Cardiovascular risk in rheumatoid arthritis: recent advances in the understanding of the pivotal role of inflammation, risk predictors and the impact of treatment. Rheumatology 2014;53:2143-54.

18 Solomon DH, Karlson EW, Rimm EB, et al. Cardiovascular morbidity and mortality in women diagnosed with rheumatoid arthritis. Circulation 2003;107:1303-7.

19 Lauper K, Gabay C. Cardiovascular risk in patients with rheumatoid arthritis. Semin Immunopathol 2017;39:447-59.

20 England BR, Thiele GM, Anderson DR, et al. Increased cardiovascular risk in rheumatoid arthritis: mechanisms and implications. BMJ 2018;361:k1036.

21 Zou K, Xiao F-K, Li H-Y, et al. Risk of cardiovascular disease in Chinese patients with rheumatoid arthritis: a cross-sectional study based on hospital medical records in 10 years. PLoS One 2017;12:e0180376. 
22 Rhew K. The risk of cardiovascular disease and diabetes in rheumatoid arthritis patients: a propensity score analysis. Korean $\mathrm{J}$ Clin Pharm 2019;29:109-14.

$23 \mathrm{Ra}$ JS, Kim HS, Jeong Y-H. Associated factors of ischemic heart disease identified among post-menopausal women. Osong Public Health Res Perspect 2019;10:56-63.

24 Lee $\mathrm{HH}$, Cho SMJ, Lee $\mathrm{H}$, et al. Korea heart disease fact sheet 2020 analysis of nationwide data. Korean Circ J 2021;51:495-503.

25 Kang MS, Kim CH, Jeong SJ, et al. Dietary sodium intake in people with diabetes in Korea: the Korean National health and nutrition examination survey for 2008 to 2010 . Diabetes Metab J 2016;40:290-6.

26 Seo JE, Lee HS, Lee SW, et al. The association between urinary sodium excretion and metabolic syndrome in Korean adults from the 2010-2011 Korean National health and nutrition examination survey. Korean J Fam Med 2017;38:199-205.

27 McLean RM, Farmer VL, Nettleton A, et al. Twenty-Four-Hour diet recall and diet records compared with 24-hour urinary excretion to predict an individual's sodium consumption: a systematic review. $J$ Clin Hypertens 2018;20:1360-76.

28 McLean R, Cameron C, Butcher E, et al. Comparison of 24-hour urine and 24-hour diet recall for estimating dietary sodium intake in populations: a systematic review and meta-analysis. J Clin Hypertens 2019;21:1753-62.

29 Tanaka T, Okamura T, Miura K, et al. A simple method to estimate populational 24-h urinary sodium and potassium excretion using a casual urine specimen. J Hum Hypertens 2002;16:97-103.

30 World Health Organization. How to obtain measures of populationlevel sodium intake in 24-hour urine samples. World Health Organization. Regional Office for the Eastern Mediterranean 2018.

31 Dong J, Yan $\mathrm{Y}$, Fan $\mathrm{H}$, et al. Accuracy validation of 8 equations to estimate 24 -hour sodium by spot urine in young adolescents. Am J Hypertens 2019;32:257-64.

32 Brown IJ, Dyer AR, Chan Q, et al. Estimating 24-hour urinary sodium excretion from casual urinary sodium concentrations in Western populations: the INTERSALT study. Am J Epidemiol 2013;177:1180-92.

33 Jeong H, Baek SY, Kim SW, et al. Comorbidities of rheumatoid arthritis: results from the Korean National health and nutrition examination survey. PLoS One 2017;12:e0176260.

34 Choi IA, Park SH, Cha H-S, et al. Prevalence of co-morbidities and evaluation of their monitoring in Korean patients with rheumatoid arthritis: comparison with the results of an international, crosssectional study (COMORA). Int J Rheum Dis 2018;21:1414-22.

35 Peters MJL, van Halm VP, Voskuyl AE, et al. Does rheumatoid arthritis equal diabetes mellitus as an independent risk factor for cardiovascular disease? A prospective study. Arthritis Rheum 2009;61:1571-9.
36 Lee TH, Song GG, Choi SJ, et al. Relationship of rheumatoid arthritis and coronary artery disease in the Korean population: a nationwide cross-sectional study. Adv Rheumatol 2019;59:40.

37 Jeong Y, Kim ES, Lee J, et al. Trends in sodium intake and major contributing food groups and dishes in Korea: the Korea National health and nutrition examination survey 2013-2017. Nutr Res Pract 2021;15:382.

38 Poggio R, Gutierrez L, Matta MG, et al. Daily sodium consumption and CVD mortality in the general population: systematic review and meta-analysis of prospective studies. Public Health Nutr 2015;18:695-704.

39 Cook NR, Appel LJ, Whelton PK. Lower levels of sodium intake and reduced cardiovascular risk. Circulation 2014;129:981-9.

40 Tuomilehto J, Jousilahti P, Rastenyte D, et al. Urinary sodium excretion and cardiovascular mortality in Finland: a prospective study. Lancet 2001;357:848-51.

41 O'Donnell MJ, Yusuf S, Mente A, et al. Urinary sodium and potassium excretion and risk of cardiovascular events. JAMA 2011;306:2229-38.

42 Liu H, Gao X, Zhou L, et al. Urinary sodium excretion and risk of cardiovascular disease in the Chinese population: a prospective study. Hypertens Res 2018;41:849-55.

43 Park CY, Jo G, Lee J, et al. Association between dietary sodium intake and disease burden and mortality in Koreans between 1998 and 2016: the Korea National health and nutrition examination survey. Nutr Res Pract 2020;14:501-18.

44 Sigaux J, Semerano L, Favre G, et al. Salt, inflammatory joint disease, and autoimmunity. Joint Bone Spine 2018;85:411-6.

45 Minamino $\mathrm{H}$, Katsushima M, Hashimoto M, et al. Urinary sodium-topotassium ratio associates with hypertension and current disease activity in patients with rheumatoid arthritis: a cross-sectional study. Arthritis Res Ther 2021;23:96.

46 Hashimoto $\mathrm{H}$, Nomura N, Shoda W, et al. Metformin increases urinary sodium excretion by reducing phosphorylation of the sodiumchloride cotransporter. Metabolism 2018;85:23-31.

47 Liu C, Zhao Q, Zhen Y, et al. Effect of corticosteroid on renal water and sodium excretion in symptomatic heart failure: prednisone for renal function improvement evaluation study. $J$ Cardiovasc Pharmacol 2015;66:316-22.

48 Shah S, Pitt B, Brater DC, et al. Sodium and fluid excretion with torsemide in healthy subjects is limited by the short duration of diuretic action. J Am Heart Assoc 2017;6:e006135.

49 Cogswell ME, Mugavero K, Bowman BA, et al. Dietary sodium and cardiovascular disease risk-measurement matters. $N$ Engl J Med 2016;375:580-6.

50 Cobb LK, Anderson CAM, Elliott P, et al. Methodological issues in cohort studies that relate sodium intake to cardiovascular disease outcomes: a science Advisory from the American heart association. Circulation 2014;129:1173-86. 